\title{
Comparative Recruitment Dynamics of Alewife and Bloater in Lakes Michigan and Huron
}

\author{
Paris D. Collingsworth*1 \\ Cooperative Institute for Limnology and Ecosystems Research, \\ School of Natural Resources and Environment, University of Michigan, G1 10 Dana Building, \\ 440 Church Street, Ann Arbor, Michigan 48109-1041, USA
}

\author{
David B. Bunnell, Charles P. Madenjian, and Stephen C. Riley \\ U.S. Geological Survey, Great Lakes Science Center, 1451 Green Road, Ann Arbor, \\ Michigan 48105, USA
}

\begin{abstract}
The predictive power of recruitment models often relies on the identification and quantification of external variables, in addition to stock size. In theory, the identification of climatic, biotic, or demographic influences on reproductive success assists fisheries management by identifying factors that have a direct and reproducible influence on the population dynamics of a target species. More often, models are constructed as one-time studies of a single population whose results are not revisited when further data become available. Here, we present results from stock recruitment models for Alewife Alosa pseudoharengus and Bloater Coregonus hoyi in Lakes Michigan and Huron. The factors that explain variation in Bloater recruitment were remarkably consistent across populations and with previous studies that found Bloater recruitment to be linked to population demographic patterns in Lake Michigan. Conversely, our models were poor predictors of Alewife recruitment in Lake Huron but did show some agreement with previously published models from Lake Michigan. Overall, our results suggest that external predictors of fish recruitment are difficult to discern using traditional fisheries models, and reproducing the results from previous studies may be difficult particularly at low population sizes.
\end{abstract}

Understanding factors that regulate recruitment is one of the primary goals of fisheries management. Towards that end, population-specific stock-recruitment models have been the conventional method to predict recruitment, but they have had mixed success because their overly simplistic structure does not account for complex interacting factors that are believed to control recruitment for many fish species, particularly at population levels that are not very high or are very low (Hilborn and Walters 1992; Walters and Martell 2004). One improvement to stock-recruitment models that is consistent with movement towards ecosystem-based management (Lester et al. 2010, and references therein) has been the addition of external variables to account for factors other than stock size. Some common external variables include the biomass of predators, system productivity, and climatic variables, such as winter warming rates and ocean circulation patterns.

Additional methodologies can be undertaken to improve the applicability of stock-recruitment models. For example, stock-recruitment models are most often published as one-off studies that are parameterized for a specific system and are, therefore, misapplied as general tools for fisheries management (Walters and Martell 2004). In response, previously published

\footnotetext{
*Corresponding author: collingsworth.paris@epa.gov

${ }^{1}$ Present address: Illinois-Indiana Sea Grant, Department of Forestry and Natural Resources, Purdue University, 195 Marsteller Street, West Lafayette, Indiana 47907-2033, USA.

Color versions of one or more of the figures in this article can be found online at www.tandfonline.com/utaf.

Received March 22, 2013; accepted August 6, 2013
} 
stock-recruitment models should be retested when new data become available to determine whether the model can reproduce consistent results across a longer time series. Unfortunately, such retests are rarely attempted and, when they are conducted, are often unable to reproduce the initial results, particularly when environmental predictors are included (Myers 1998). A second approach to improve the robustness of stock-recruitment models is to analyze multiple populations simultaneously to identify common environmental predictors across the geographic range of the species of interest. This approach has had more success identifying correlations between environmental variables and recruitment (Langley et al. 2009), but acquiring comparable data sets across multiple stocks or systems can be difficult.

Researchers in the Laurentian Great Lakes have previously developed models that seek to go beyond conventional stockrecruitment models by incorporating external variables. For example, Madenjian et al. (1996) explained $92 \%$ of the variation in Walleye Sander vitreus recruitment in western Lake Erie by including the fall abundance of Gizzard Shad Dorosoma cepedianum and spring warming, as well as stock size. Similarly, Bunnell et al. (2006) found that nearly all of the variation in Bloater Coregonus hoyi recruitment in Lake Michigan could be explained by including population egg production, sex ratio, winter severity, and the adult condition into a dynamic linear model. Looking across studies, similar patterns for a given species have begun to emerge across multiple lakes. For example, salmonine predation and summer temperatures appear to have a similar influence on recruitment success of Alewives Alosa pseudoharengus in Lakes Ontario (O'Gorman 2004) and Michigan (Madenjian et al. 2005). The recruitment of Bloaters also can be synchronous across Lakes Superior, Michigan, and Huron (Bunnell et al. 2010), which suggests that some regional factor such as climate may be exerting similar effects across broad spatial scales. Unfortunately, however, models that explore factors underlying recruitment variability of Bloater exist only for Lake Michigan.

In this paper, we sought to improve the applicability and robustness of stock-recruitment models through a series of analyses. First, we sought to retest existing models for Bloater and Alewife in Lake Michigan now that 8 years of new data can be added for each species. Furthermore, during those years in the 2000s when data were added, the Lake Michigan ecosystem underwent numerous changes including declines in concentrations of total phosphorus and chlorophyll (Barbiero et al. 2012), as well as densities of benthic invertebrate prey (Nalepa et al. 2009) and other planktivorous and benthivorous prey fishes (Bunnell et al. 2013). Second, we sought to develop new models for these two species in Lake Huron. No stock-recruitment model exists for Alewife in Lake Huron and this population collapsed between 2002 and 2003 (Riley et al. 2008). The only existing stock-recruitment model for Lake Huron did not explore the addition of external variables and included data through only 1996 (Schaeffer 2004). Lake Huron also underwent dramatic shifts in community composition and density across multiple trophic levels during the 2000s (see Bunnell et al., in press). With these newly developed models, we sought, for each species, to compare the relative importance of external variables between the two lakes. Finally, we sought to evaluate the predictive power of each models using cross-validation procedures. By retesting existing models and comparing models developed for a given species across two lakes, our overall goal was to provide managers with more robust predictive models and to further understand whether drivers of fish recruitment are common across lakes and species.

\section{METHODS}

Bottom trawls.-Annual estimates of recruitment and spawning-stock size for Alewife and Bloater were derived from U.S. Geological Survey Great Lakes Science Center (USGSGLSC) bottom trawl surveys. Each fall the USGS-GLSC samples prey fish communities in Lakes Michigan and Huron using bottom trawls at standard locations (Figure 1). Standardized sampling has been conducted since 1962 in Lake Michigan and since 1973 in Lake Huron. From 1962 to 1966, Lake Michigan bottom trawling was conducted along a single transect off Saugatuck, Michigan. From 1967 to 1972 sampling was expanded to four transects and three additional transects were added in 1973. From 1973 to the present, sampling has been conducted annually at Frankfort, Ludington, and Saugatuck, Michigan; Waukegan, Illinois; Port Washington and Sturgeon Bay, Wisconsin; and Manistique, Michigan. Data from 1998 were excluded because the trawl was towed at an unusually fast speed, which affected catchability. Throughout the Lake Michigan time series, sampling was conducted using a $\frac{3}{4}$ Yankee Standard No. 35 bottom trawl with a 12-m headrope, $15.5-\mathrm{m}$ footrope, and a 13-mm mesh cod end. In Lake Huron, annual bottom trawl surveys were conducted at five locations (De Tour, Hammond Bay, Alpena, Au Sable Point, and Harbor Beach) in Michigan waters. Data were not used from 1992 to 1993 (sampling was abnormally early) and 1998 (tow speed was too fast), and no sampling occurred in 2000. From 1973 to 1991 sampling was conducted using a 12-m-headrope trawl, whereas sampling from 1992 to the present was conducted using a 21-m-headrope trawl. Both net configurations had a cod end with $4.76-\mathrm{mm}$ stretch mesh. Fish densities from the two trawls were made comparable by multiplying by species-specific fishing power corrections (Adams et al. 2009). At each location in both lakes, a bottom trawl was towed along fixed transects at depths ranging from 9 to $110 \mathrm{~m}$ in $9-\mathrm{m}$ increments for $10 \mathrm{~min}$ and towing speeds averaged between 3 and $4 \mathrm{~km} / \mathrm{h}$ (Fleischer et al. 2000).

During 1972-2008 in Lake Michigan and throughout the Lake Huron time series, indices for Alewife and Bloater spawning-stock size and recruitment were based on "swept area" estimates calculated with the algorithm outlined in Riley et al. (2009) and Madenjian et al. (2010). All fish caught in bottom trawls were sorted by species, counted, and weighed in aggregate. When catches were greater than $20 \mathrm{~kg}$, a random sample was sorted by species, counted, and weighed, and the remainder of the catch was weighed. The catch composition was then 


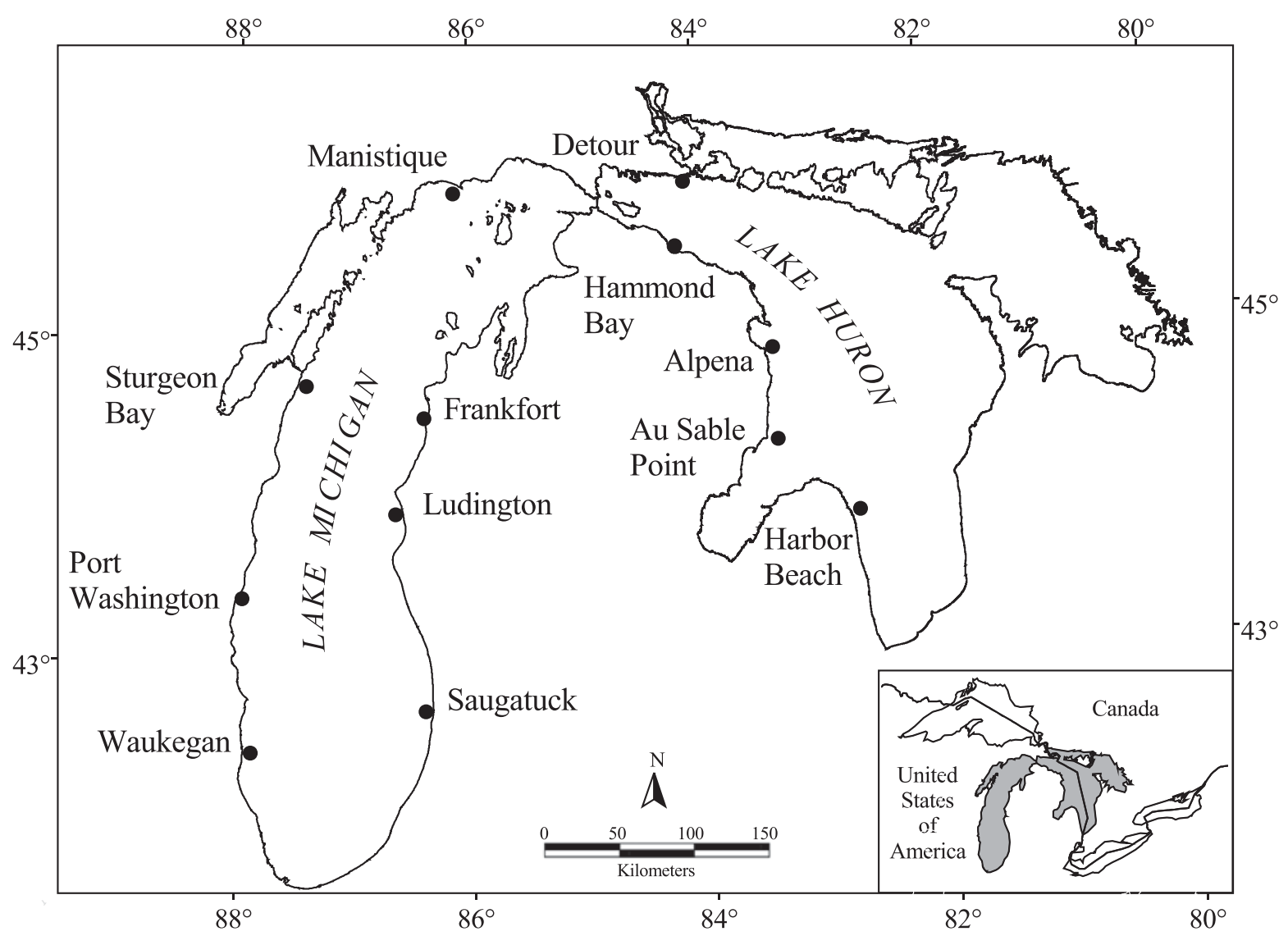

FIGURE 1. Ports in the United States sampled in Lake Michigan and Lake Huron during annual bottom trawl surveys conducted by the U.S. Geological Survey Great Lakes Science Center. At each port, prey fish were sampled along fixed transects at depths ranging from 9 to $110 \mathrm{~m}$.

estimated by direct proportion. Alewives for aging were stored on ice and processed within $24 \mathrm{~h}$ of capture. All Alewives less than $100 \mathrm{~mm}$ TL were classified as age 0 in Lake Michigan (Norden 1967; Brown 1972) and were classified by year-specific length cut-offs in Lake Huron. Fish designated as age 0 were not processed further for aging purposes. For larger individuals, up to seven Alewives from each 5-mm size-class were selected for further processing. These fish were measured to the nearest millimeter and weighed to the nearest gram. Prior to 1984, scales were used to age Alewives, but otoliths were used in more recent years. For detailed descriptions of laboratory protocols for USGS-GLSC bottom trawl surveys refer to Madenjian et al. (2005), Bunnell et al. (2006), and Riley et al. (2008).

Constructing Alewife and Bloater time series.-All Alewife and Bloater indices between 1962 and 1972 in Lake Michigan were extrapolated from bottom trawl data at seven depth intervals from a single port, Saugatuck. Briefly, a conversion factor was calculated as the ratio of the average lakewide density and biomass based on the data collected at all available ports and depth strata over the period 1973-2008; the lakewide density and biomass were calculated solely from the Saugatuck transects over the same time period (Madenjian et al. 2005). Lake Michigan recruitment and spawning-stock indices for Alewife and Bloater during 1962-1972 were then estimated by multiplying the swept-area estimates from the Saugatuck transect by the appropriate conversion factors.

Alewife stock-recruitment indices were developed from the Lake Michigan and Lake Huron bottom trawl time series. Alewife recruitment was defined as the lakewide biomass of age-3 Alewives. Recruitment was set at age 3 because catches of younger Alewives are not indicative of year-class strength in Lake Michigan (Madenjian et al. 2005). Spawning-stock size was defined as the biomass of Alewives greater than or equal to $150 \mathrm{~mm}$ TL from 3 years previously. We chose this estimate of spawning-stock biomass because Alewives greater than or equal to $150 \mathrm{~mm}$ are typically sexually mature (Brown 1972) and biomass is a more reliable estimate of spawning effort than number of spawners (Hilborn and Walters 1992). Alewife recruitment was calculated in two steps. First, biomass of Alewives age 1 and older was estimated using the swept-area biomass of Alewives greater than or equal to $100 \mathrm{~mm}$. Then, the proportion of age-3 fish was estimated using age-length keys (DeVries and Frie 1996) for each year with sufficient aging data (see Madenjian el al. 2005 for aging protocols). The proportions generated from age-length keys were then multiplied by the biomass of age- 1 and older fish to obtain an estimate of age-3 fish. 
Bloater recruitment was defined as the lakewide density (number fish/ha) of age-0 Bloaters. We chose to use age-0 abundance as our measure of Bloater recruitment because aging data were not available for all years in the Lake Huron time series and, although they are not fully recruited to the bottom trawls, the abundance of age- 0 Bloaters is positively correlated with age-3 Bloaters (Bunnell et al. 2010). Because Bloaters were inconsistently aged across years and lakes, the number of age- 0 Bloaters was determined by visual inspection of length frequency plots for each year in the time series to establish a year-specific length cut-off. Bloater spawning-stock size was defined as population egg production for all fish greater than or equal to $180 \mathrm{~mm}$ TL. Population egg production was estimated using length distributions of adult Bloaters greater than or equal to $180 \mathrm{~mm}$ along with estimates of size-specific fecundity. Because the relationship between Bloater weight and fecundity has changed through time (Bunnell et al. 2009), we used two different weightbased fecundity estimates. Before 1983, we used the weightfecundity relationship of Emery and Brown (1978) where fecundity $=-580.6+58.88 \times$ (weight in grams), whereas the relationship identified in Bunnell et al. (2009) where fecundity $=$ $-1990.1+56.5 \times$ (weight in grams) was used in subsequent years.

Constructing time series for external variables.-External variables used to explain recruitment variation in Alewife and Bloater differed between species and were selected based on their appearance in previously published recruitment models for each species (Madenjian et al. 2005; Bunnell et al. 2006) and their representation of hypothesized bottlenecks to recruitment (Table 1). To construct an index of salmonine biomass (SALMON), we used the combined lakewide biomass of Chinook Salmon Oncorhynchus tshawytscha and Lake Trout Salvelinus namaycush in Lake Michigan (Madenjian et al. 2005, I. Tsehaye, Michigan State University, unpublished data; D. Carrofino, Michigan Department of Natural Resources, unpublished data) and Lake Huron (T. Brendon, Michigan State University, and J. He, Michigan Department of Natural Resources, unpublished data). Salmonine biomass estimates were generated from age-structured models that were parameterized using statistical catch-at-age methods (Benjamin and Bence 2003). For 1962 1965 in Lake Michigan, salmonine biomass was assumed to be zero because the major salmonine stocking program in Lake Michigan did not begin until 1965.

For our Alewife models, indices of lakewide spring-summer temperatures (SUMMER) and winter severity (WINTER) were generated using a model of evaporation and thermal fluxes developed by the Great Lakes Environmental Research Laboratory (GLERL; Croley 1995). Using daily inputs of air temperature, wind speed, humidity, and cloud cover from around the Great Lakes, the model generates daily lakewide average temperature at depth in 1-m increments. To calculate the SUMMER index, we first calculated daily integrated average water temperatures for the top $20 \mathrm{~m}$ of each lake from May 1 through August 31 . The annual SUMMER index was then calculated as the average daily water temperatures in each lake during this interval. To calculate the WINTER index, we calculated daily integrated water temperatures for the entire water column of each lake from December 1 through April 30. The annual WINTER index was then calculated as the number of days during this interval when the daily average water temperature was less than $4^{\circ} \mathrm{C}$ during that time interval. We hypothesized that warm summers would positively influence Alewife recruitment because they provide an optimum growth environment for spring-spawned Alewives (Madenjian et al. 2005). Conversely, cold winters may induce winterkill events that would negatively influence Alewife recruitment (O'Gorman and Schneider 1986). The lake level (LEVEL) index was constructed using data from the U.S. Army Corps of Engineers Detroit District historical water level time series. Because the two lakes share a hydrological connection, a single water level table, referenced to the International Great Lakes Datum 1985, was generated from historical gauging data for both lakes. The annual LEVEL index was calculated as the annual average lake water level during May-June for Lakes Michigan and Huron. High lake levels were expected to have a positive influence on Alewife recruitment by increasing the amount of potential spawning habitat.

TABLE 1. Summary of external variables (and their hypothesized mechanisms) used in models to explain Alewife and Bloater recruitment in Lakes Michigan and Huron. Plus sign "+" = positive effect, minus sign "-" = negative effect, and NA = not applicable.

\begin{tabular}{lcc}
\hline & \multicolumn{2}{c}{ Species } \\
\cline { 2 - 3 } Variable & \multicolumn{1}{c}{ Alewife } & Bloater \\
\hline LEVEL & $(+)$ Increased spawning habitat & NA \\
SALMON & $(-)$ Predation on all life stages & NA \\
SUMMER & $(+)$ Warmer growth environment & NA \\
WINTER & $(-)$ Winterkill & NA \\
ALEWIFE & NA & (-) Predation on larvae \\
K & NA & (+) Increased egg production \\
SEX & NA & (-) Limited number of females \\
W-S & NA & (+) Shorter egg incubation \\
\hline
\end{tabular}


Indices of adult Bloater condition and population sex ratio were calculated using biological data collected by USGSGLSC. Indices of population sex ratio (SEX) were calculated as the percentage of adult female Bloaters collected in bottom trawls. We expect low recruitment of Bloaters during periods with highly skewed sex ratios, possibly due to a limited number of males available for spawning. Fulton's condition index $[\mathrm{K}=$ $\left(\right.$ weight/length $\left.{ }^{3}\right) \times 10^{5}$ ] was used as a measure of adult Bloater condition. In Lake Michigan from 1967 to 2009, K was calculated for all age-2 and older Bloaters. For the years before 1967 in Lake Michigan and for the entire Lake Huron time series, $\mathrm{K}$ equaled the average condition index for all fish greater than $165 \mathrm{~mm}$. Adult Bloater condition and population sex ratio could not be calculated in Lake Huron for 12 of the 36 years in the time series because adequate biological data were not available. During these years, index values from Lake Michigan were used to fill gaps in the Lake Huron time series. We felt that this substitution was justified because of the correlation between annual $\mathrm{K}$ values for each lake for years with comparable data $(r=$ $0.37, P=0.05$ ). In general, more positive $\mathrm{K}$ values should have a positive effect on recruitment because of maternal effects on egg and larval quality. For our indices of adult Alewife biomass (ALEWIFE) we used the spawning-stock biomass calculation describe above for Alewife. We expect that high Alewife abundance will negatively influence Bloater recruitment due to increased predation on larvae. To construct an index of winter and spring temperatures for bloater (W-S), we calculated the average daily water temperature at depths between 40 and $110 \mathrm{~m}$ from January 1 through June 30 using temperature profile data from the GLERL model described above. The annual W-S index was calculated as the average daily integrated temperature. Taking cues from the life history of Bloater (see Rice et al. 1987), the $\mathrm{W}-\mathrm{S}$ index was expected to be positively correlated with Bloater recruitment because warmer water temperatures during this period should have led to shorter egg development times.

Statistical time series analyses.-Alewife stock-recruitment relationships were assessed using a standard Ricker spawnerrecruit model (Ricker 1975):

$$
R=S e^{[a-b S]} e^{\varepsilon},
$$

where $R=$ the lakewide biomass of age-3 recruits (in kilotons), $S=$ the lakewide biomass of Alewives greater or equal to $150 \mathrm{~mm}$, and $e^{\varepsilon}$ is the lognormal error term. External variables were added to the standard Ricker model and both sides of the equation were $\log _{e}$ transformed, resulting in the following equation:

$$
\log _{e}[R]=\log _{e}[S]+\alpha-b S+\sum_{i} c_{i} X_{i}+\varepsilon,
$$

where $X_{i}$ is external variable $i$. The Ricker model was selected because Alewife populations in the Great Lakes display densitydependent recruitment (O'Gorman et al. 2004; Madenjian et al.
2005) and because an initial analysis of the data found no temporal autocorrelation in Alewife recruitment from Lake Michigan or Lake Huron $(P>0.16$ for all models results analyzed with Portmanteau test). Before fitting each Ricker model, all explanatory variables were standardized by subtracting the mean and dividing by the SD to allow for direct comparisons of the regression coefficients. Parameters for Alewife stock recruitment models were estimated using nonlinear regression (nls) in the program R (R Development Core Team, 2008) and residuals from the fitted models were used to calculate the negative loglikelihood (NLL) for each model:

$$
\mathrm{NLL}=n\left[\log _{e}(\sigma)+0.5 \log _{e}(2 \pi)\right]+\mathrm{SSE} / 2 \sigma^{2},
$$

where $n$ is the number of observations, SSE is the sum of the squared residuals, and $\sigma^{2}$ is the SSE divided by $n$ (Hilborn and Mangel 1997).

Bloater stock-recruitment relationships were assessed using a Bayesian time series model, dynamic linear models (DLMs). Dynamic linear models were used because the Bloater recruitment time series displayed considerable temporal autorcorrelation in both lakes and these models have been used in the past to analyze Bloater recruitment in Lake Michigan (Bunnell et al. 2006). Each DLM consists of two time-dependent equations: an observation equation and a system equation. In the observation equation, the response variables $\left(Y_{t}\right)$ are sequentially fitted to a $1 \times m$ vector of predictor variables $\left(\boldsymbol{X}_{\boldsymbol{t}}\right)$ with a $m \times 1$ vector of model parameters $\left(\boldsymbol{\theta}_{t}\right)$ and a normally distributed error term $\left(v_{t}\right)$ :

$$
Y_{t}=\boldsymbol{X}_{\boldsymbol{t}} \boldsymbol{\theta}_{t}+v_{t}, v_{t} \sim \mathrm{N}\left(0, V_{t}\right)
$$

where $m$ represents the number of predictor variables considered plus a level and growth parameter associated with the dynamic linear trend. Variance in observation errors are time dependent $\left(V_{t}\right)$ and are estimated from prior data using a discounting factor that determines the number of years to use. The systems equation allows the model parameters $\left(\boldsymbol{\theta}_{t}\right)$ to change with each time step through a first order Markov process:

$$
\boldsymbol{\theta}_{t}=\boldsymbol{G} \boldsymbol{\theta}_{t-1}+\omega_{t}, \omega_{t} \sim \mathrm{N}\left(0, \mathbf{W}_{t}\right),
$$

where $\boldsymbol{G}$ is the $m \times m$ system evolution matrix that determines how the model parameters change and $\boldsymbol{\omega}_{\boldsymbol{t}}$ is the $m \times 1$ vector that described the stochastic change in normally distributed parameters through time. The system covariance matrix, $\boldsymbol{W}_{t}$, describes the variance of the parameters through time and a discount factor is again applied to determine the amount of prior data used in the estimation at each time step. Before fitting each DLM, we $\log _{\mathrm{e}}$-transformed the response variables and standardized the explanatory variables as described above.

The discount factors applied to $V_{t}$ and $\boldsymbol{W}_{\boldsymbol{t}}$ allow the model flexibility in assigning the importance of recent observations when predicting model parameters and variance for the next time step. Here, we followed the advice of Pole et al. (1994) 
by setting all discount factors to greater than or equal to 0.8 and always setting the discount factor for the regression parameters greater than that for the trend parameters (i.e., level and growth parameters, respectively). However, the difference between the regression and the trend discounts was never greater than 0.1, as recommended by Pole et al. (1994). Before fitting each model, we systematically varied discount factors until the combination that maximized the log-likelihood in the forecast model was identified. Once the appropriate combination of discount factors was identified, we retrospectively fit the data and used the residuals to calculate NLL for each model. All DLMs were analyzed using the BATS statistical package (Pole et al. 1994).

For Alewife models, we used second-order Akaike's information criterion corrected for small sample size $\left(\mathrm{AIC}_{c}\right)$ to determine which models were best supported by the data (Akaike 1973; Burnham and Anderson 2002). For each lake, we fit 16 different Alewife Ricker stock-recruit candidate models with spawning-stock biomass (included in all models) plus all possible combinations of the four external variables (LEVEL, SALMON, SUMMER, and WINTER; Table 1). The $\mathrm{AIC}_{c}$ was calculated from the residuals of each fitted model using the following form:

$$
\mathrm{AIC}_{c}=[n \log (\mathrm{SSE} / n)+2 K]+2 K(K+1) /(n-K-1),
$$

where $n$ is the number of years in the time series, SSE is the sum of the squared residuals, and $K$ is the total number of regression parameters. Because $\mathrm{AIC}_{c}$ is only meaningful relative to the other $\mathrm{AIC}_{c}$ values in the model set (Burnham and Anderson 2002), comparisons of fits across the model sets in each lake were made using $\mathrm{AIC}_{c}$ differences $\left(\triangle \mathrm{AIC}_{c}\right)$. Models with $\Delta \mathrm{AIC}_{c}$ values of $0-2$ show substantial empirical support and were considered the best models, whereas models with $\Delta \mathrm{AIC}_{c}$ values greater than 4 have considerably less support. The relative likelihood of a model, given the data and a set of models was determined using Akaike weights $\left(w_{i}\right)$.

For Bloater DLMs, we considered population egg production plus all possible combinations of the four external variables (SEX, K, W-S and ALEWIFE; Table 1), but also included a reference model that contained only the level and growth parameters for a total of 17 candidate models. In concordance with previously published work, we used Bayesian Information Criterion to rank competing models (Bunnell et al. 2006):

$$
\mathrm{BIC}=2(\mathrm{NLL})+m\left[\log _{e}(n)\right],
$$

where $m$ is the number of estimated parameters plus the observation variance estimate, NLL is the negative log-liklihood, and $n$ is the sample size.

When more than one Ricker model in the set had some level of support (i.e., $\Delta \mathrm{AIC}_{c}<4$ ), we calculated predicted Alewife recruitment using multimodel averages to incorporate model selection uncertainty into our estimates of recruitment (Burn- ham and Anderson 2002). When model selection uncertainty occurred, parameter coefficients for external variables are reported as a range of values; otherwise, parameter coefficients are reported for the best model. The relative importance of individual external variables was determined by summing $w_{i}$ across all models that contained the variables of interest for a given lake and species.

Model cross validation.-Robustness of model-derived predictions of alewife recruitment was assessed using a cross-validation procedure adapted from Francis (2006). Our cross-validation approach for the Alewife models began by determining 20th percentiles for annual recruitment in each lake. A "validating" data set was then generated by randomly excluding all data from an equal number of years in each percentile grouping until $20 \%$ of the observations were removed from each time series. The remaining $80 \%$ of the time series was then used as a "training" data set. By sampling equally from all percentiles, we insured that both the training and validation data sets contained the full range of values of observed recruitment. Separate models were then fit to the training data set using the candidate models with $\Delta \mathrm{AIC}_{c}$ values less than 4 . This fitting created new parameter coefficients for each candidate model. New coefficients for each candidate model were then used to predict recruitment for the validating data set. Model performance during cross-validation procedures was evaluated in two ways. First, mean square error (MSE) of the predicted recruitment $(r)$ for each candidate model was calculated:

$$
\operatorname{MSE}=\sum\left(r_{\text {obs }}-r_{\text {pred }}\right)^{2} / n,
$$

where $r_{\text {obs }}$ is the observed recruitment from the validating data set, $r_{\text {pred }}$ is the predicted recruitment calculated using the coefficients derived from the training data set, and $n$ is the number of years in the validating data set (10 and 5 for Lake Michigan and Lake Huron, respectively). This process was repeated five times and the average MSE and SE for each candidate model were calculated from the cross-validation runs. Secondly, we evaluated model performance using linear regression to determine the relationship between observed and predicted recruitment for Alewives over the five validation runs. In the linear regression analyses, robust recruitment models will have a slope equal to or near one and a high coefficient of determination. Due to the time-variant nature of DLMs, we were unable to cross validate the Bloater recruitment models.

\section{RESULTS}

Multiple candidate models generally provided the most empirical support for Alewife recruitment in Lakes Michigan and Huron. For Lake Michigan Alewife, four models had $\Delta \mathrm{AIC}_{c}$ values less than 2 and were indistinguishable from one another in providing the best explanation for variation in Alewife recruitment in Lake Michigan (Table 2), and the SALMON, WINTER, and SUMMER indices were included in the top four models. Looking across the entire set of models, 14 of the 16 models 
TABLE 2. Results from fitting Ricker stock-recruit models of lakewide biomass estimates of age-3 Alewife recruits to lakewide biomass estimates of the parental stock $\left(\beta_{\mathrm{S}}\right)$ and external variables in Lake Michigan for the years 1965-2008. The external variables and their coefficient labels were as follows: SALMON $=$ Salmonine abundance $\left(\beta_{\text {Sal }}\right)$; SUMMER $=$ summer temperature index $\left(\beta_{\text {Sum }}\right) ;$ LEVEL $=$ average water level $\left(\beta_{\mathrm{L}}\right)$; WINTER $=$ index of winter severity $\left(\beta_{\text {Win }}\right)$. Akaike's information criterion $\left(\mathrm{AIC}_{c}\right)$ values were used to rank the models. When the difference in $\mathrm{AIC}_{c}$ values $(\Delta \mathrm{AIC})$ is $<2$, there is equal support for the models. Certainty in model selection was evaluated using standardized Akaike weights $\left(w_{i}\right)$, which are scaled from 0 to 1.

Values of regression coefficients

\begin{tabular}{|c|c|c|c|c|c|c|c|c|c|c|}
\hline \multirow{2}{*}{$\begin{array}{l}\text { Model } \\
\text { rank }\end{array}$} & \multirow[b]{2}{*}{ List of external variables } & \\
\hline & & $\alpha$ & $\beta_{S}$ & $\beta_{\text {Sal }}$ & $\beta_{\text {Sum }}$ & $\beta_{\text {Lev }}$ & $\beta_{\text {Win }}$ & $\mathrm{AIC}_{c}$ & $\Delta \mathrm{AIC}_{c}$ & $w_{i}$ \\
\hline 1 & SALMON & -0.779 & 0.011 & -0.473 & & & & -3.179 & 0.000 & 0.210 \\
\hline 2 & SALMON, WINTER & -0.750 & 0.012 & -0.423 & & & 0.259 & -2.639 & 0.540 & 0.160 \\
\hline 3 & SALMON, SUMMER, WINTER & -0.787 & 0.011 & -0.478 & 0.308 & & 0.419 & -1.635 & 1.544 & 0.097 \\
\hline 4 & WINTER & -0.954 & 0.008 & & & & 0.324 & -1.296 & 1.883 & 0.082 \\
\hline 5 & & -1.022 & 0.006 & & & & & -1.156 & 2.023 & 0.076 \\
\hline 6 & SALMON, LEVEL & -0.776 & 0.011 & -0.487 & & 0.036 & & -0.779 & 2.400 & 0.063 \\
\hline 7 & SALMON, SUMMER & -0.785 & 0.011 & -0.484 & 0.037 & & & -0.770 & 2.408 & 0.063 \\
\hline 8 & SALMON, LEVEL, WINTER & -0.752 & 0.012 & -0.381 & & -0.092 & 0.301 & -0.287 & 2.892 & 0.049 \\
\hline 9 & LEVEL, WINTER & -0.908 & 0.009 & & & -0.228 & 0.411 & -0.193 & 2.986 & 0.047 \\
\hline 10 & SUMMER, WINTER & -0.993 & 0.007 & & 0.187 & & 0.426 & 0.660 & 3.838 & 0.031 \\
\hline 11 & LEVEL & -1.011 & 0.006 & & & -0.090 & & 0.955 & 4.133 & 0.027 \\
\hline 12 & SUMMER & -0.993 & 0.007 & & -0.090 & & & 1.009 & 4.188 & 0.026 \\
\hline 13 & SALMON, SUMMER, WINTER, LEVEL & -0.787 & 0.011 & -0.460 & 0.297 & -0.035 & 0.429 & 1.045 & 4.224 & 0.025 \\
\hline 14 & SALMON, SUMMER, LEVEL & -0.786 & 0.011 & -0.515 & 0.067 & 0.062 & & 1.711 & 4.890 & 0.018 \\
\hline 15 & SUMMER, LEVEL, WINTER & -0.942 & 0.008 & & 0.150 & -0.214 & 0.487 & 2.053 & 5.232 & 0.015 \\
\hline 16 & SUMMER, LEVEL & -0.963 & 0.008 & & -0.136 & -0.127 & & 3.078 & 6.257 & 0.009 \\
\hline
\end{tabular}

had $\Delta \mathrm{AIC}_{c}$ values less than 4 , which suggests that nearly all of the models in the Lake Michigan Alewife analyses had some level of support (Table 2). Despite a high level of model selection uncertainty, the multimodel average of predicted Alewife recruitment for Lake Michigan provided an accurate description of the trends in the Alewife recruitment time series (Figure 2). The relative importance of the external variables differed across lakes for the Alewife recruitment time series. Using the sum of the AIC weights $\left(w_{i}\right)$, the SALMON index was the most important predictive variable in Lake Michigan, followed by WINTER, SUMMER, and LEVEL. All eight of the models that contained the SALMON index appeared in the top-14-ranked models and the sum of the $w_{i}$ values for these models was 0.69. The calculated regression coefficients for the SALMON index indicate that salmonine predation exerts a consistent negative influence on Alewife recruitment in Lake Michigan (SALMON coefficient ranged between -0.515 and -0.381 ). The second most important variable used to describe Alewife recruitment in Lake Michigan was the WINTER index, for which the sum of the $w_{i}$ values was 0.51 . Regression coefficients $(0.26-0.49)$ revealed that winter severity has a positive influence on Alewife recruitment in Lake Michigan. The sum of the $w_{i}$ values for the SUMMER and LEVEL indices were low (0.28 and 0.25, respectively) and appear to be less important predictors of Alewife recruitment in Lake Michigan.

An even lower level of certainty was detected when selecting the best model to describe the Alewife stock-recruitment rela- tionship in Lake Huron. Two models had $\triangle \mathrm{AIC}_{c}$ values of less than 2 and were indistinguishable from one another, the basic Ricker model with no external variables, and the Ricker model with the LEVEL index. However, across the entire model set, a total of eight models had $\triangle \mathrm{AIC}_{c}$ values less than 4 (Table 3 ) and all of these models were used to provide a multimodel average estimate of Alewife recruitment for the Lake Huron time series (Figure 2B). Given that few external variables were included in the candidate models with the lowest $\Delta \mathrm{AIC}_{c}$ values, our external variables do not appear to be important predictors of Alewife recruitment in Lake Huron. Across the entire model set, the sums of the $w_{i}$ values were below 0.5 for all external variables for the Lake Huron time series and only one variable, the LEVEL index, had a value above 0.25 (Figure 3a). Water levels appear to have had a positive influence on Alewife recruitment in Lake Huron (LEVEL coefficients ranged between 0.44 and 0.55$)$.

Variation in Bloater recruitment was explained by the same set of external variables across Lakes Michigan and Huron, and Bloater recruitment models had less model selection uncertainty, overall, when compared with models for Alewife. In Lake Michigan, two models had $\triangle \mathrm{AIC}_{c}$ values less than 2: one that included the indices EGG, SEX, K, and ALEWIFE, and another that included EGG, SEX, and ALEWIFE (Table 4). In all, only three models had $\Delta \mathrm{AIC}_{c}$ values less than 4 , and these models were combined to provide a multimodel average estimate of Bloater recruitment in Lake Michigan that was indistinguishable 

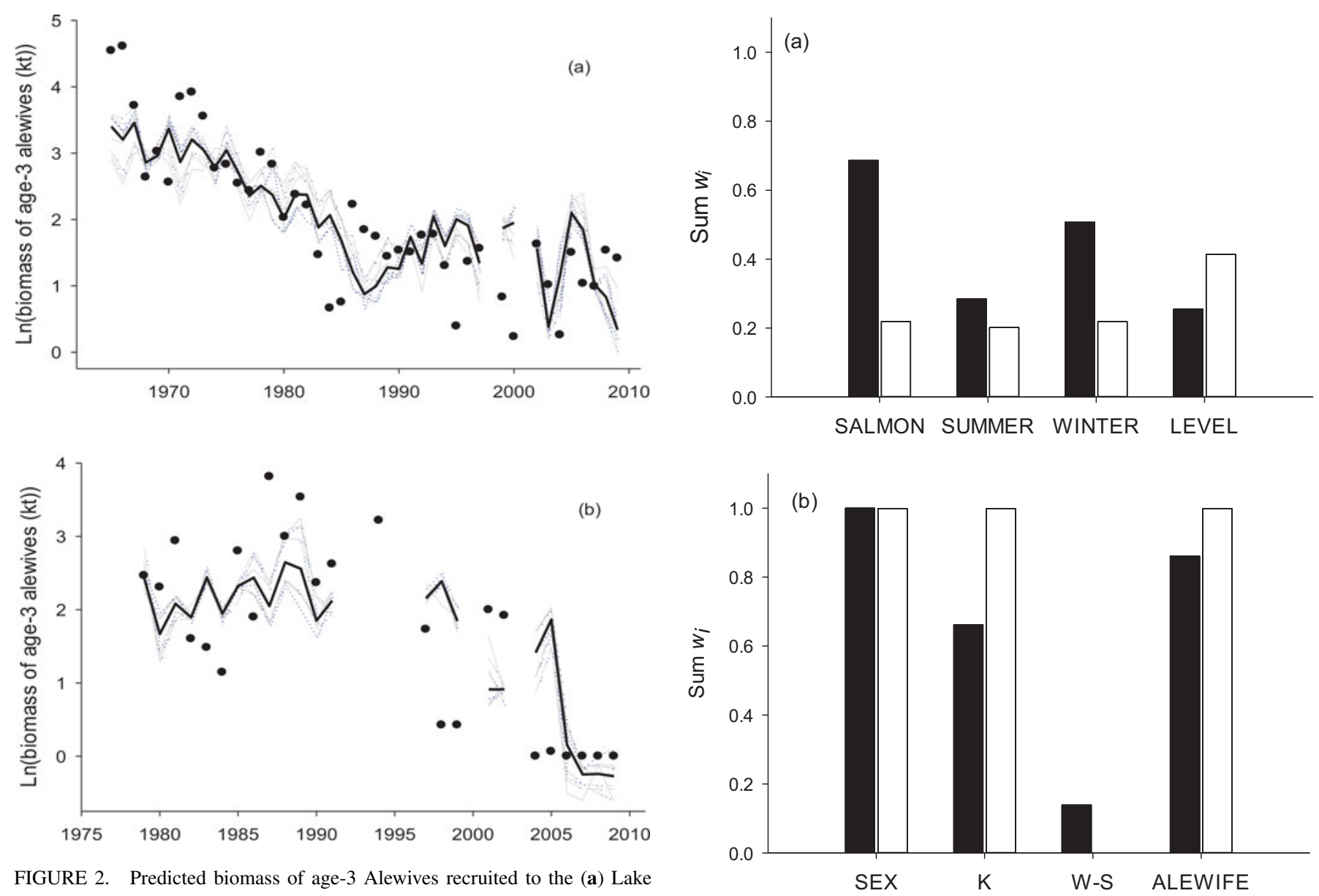

FIGURE 2. Predicted biomass of age-3 Alewives recruited to the (a) Lake Michigan population from 1965 to 2009 and (b) Lake Huron population from 1979 to 2009. Observed age-3 Alewife biomass (dots) are compared with predicted age-3 biomass from multimodel averages (solid line) for Ricker stockrecruit models with $\Delta \mathrm{AIC}_{c}$ values less than 4.

from the observed bloater recruitment (Figure 4a). In Lake Huron, the best model to describe Bloater recruitment included the indices EGG, SEX, K, and ALEWIFE, which was the same as the best model in Lake Michigan. There was no model selection uncertainty in Lake Huron, however, because all other models had $\Delta \mathrm{AIC}_{c}$ values greater than 10 (Table 5). Therefore, the best model was the only model used to predict Bloater recruitment over the Lake Huron time series (Figure 5a), and model predictions deviated markedly from the observed data.

Unlike the Alewife time series, there was considerable agreement on the relative importance of external variables between the Bloater recruitment time series in Lake Michigan and Lake Huron. According to the sum of AIC weights, the same three indices-SEX, K, and ALEWIFE-were important predictors of Bloater recruitment in both Lake Michigan and Lake Huron (Figure 3b). Unlike the Ricker models that produced a single estimated coefficient for each external variable included in a given model, DLMs allow for changes in coefficient values across a time series. The SEX indices were generally negative (meaning a higher percentage of females correlated with poor recruitment),

FIGURE 3. Summed Akaike weights $\left(w_{i}\right)$ for explanatory variables calculated from (a) the Alewife Ricker stock-recruitment models and (b) the Bloater dynamic linear model results from Lake Michigan (solid bars) and Lake Huron (open bars). Akaike weights for each external variable are summed across all the models in the set where the variable occurs (eight models per explanatory variable). The value of $w_{i}$ ranges between 0 and 1 with higher values indicating greater relative importance for explanatory variables. See Table 1 for more information about explanatory variables.

with coefficients reaching a minimum during the mid-1980s in both lakes, and becoming less negative through the latter part of the time series (Figures $4 c, 5 c$ ). The index of adult condition, $\mathrm{K}$, was positively related to Bloater recruitment in Lake Huron, but the $\mathrm{K}$ coefficient was near zero throughout most of the Lake Michigan time series, with the exception of brief time during the 1990s (Figure 4d, 5d). Finally, the ALEWIFE index appeared to have a consistent, negative impact on Bloater recruitment in both lakes, with the relationship trending more negative early and late in Lake Huron and towards the end of the time series in Lake Michigan (Figure 4e, 5e).

Results from the model cross-validation procedures revealed that the robustness of the model prediction varied with lakes and the types of models used (Table 6). Model results for Alewife in Lake Michigan were fairly robust, showing relatively low MSE values $(0.6-0.7)$ compared with the mean recruitment estimate 
TABLE 3. Results from fitting Ricker stock-recruit models of lakewide biomass estimates of age-3 Alewife recruits to lakewide biomass estimates of the parental stock $\left(\beta_{S}\right)$ and external variables in Lake Huron for the years 1979-2008. The external variables and their coefficient labels were as follows: SALMON = Salmonine abundance $\left(\beta_{\text {Sal }}\right)$; SUMMER $=$ summer temperature index $\left(\beta_{\text {Sum }}\right)$; LEVEL $=$ average water level $\left(\beta_{\mathrm{L}}\right)$; WINTER $=$ index of winter severity $\left(\beta_{\text {Win }}\right)$. Akaike's information criterion $\left(\mathrm{AIC}_{c}\right)$ values were used to rank the models. When the difference in $\mathrm{AIC}_{c}$ values $(\Delta \mathrm{AIC})$ is $<2$, there is equal support for the models. Certainty in model selection was evaluated using standardized Akaike weights $\left(w_{i}\right)$, which are scaled from 0 to 1.

\begin{tabular}{|c|c|c|c|c|c|c|c|c|c|c|}
\hline \multirow{2}{*}{$\begin{array}{l}\text { Model } \\
\text { rank }\end{array}$} & \multirow[b]{2}{*}{ List of external variables } & \multicolumn{9}{|c|}{ Values of regression coefficients } \\
\hline & & $\alpha$ & $\beta_{\mathrm{S}}$ & $\beta_{\text {Sal }}$ & $\beta_{\text {Sum }}$ & $\beta_{\text {Lev }}$ & $\beta_{\text {Win }}$ & $\mathrm{AIC}_{c}$ & $\Delta \mathrm{AIC}_{c}$ & $w_{i}$ \\
\hline 1 & & -0.158 & 0.029 & & & & & 4.632 & 0.000 & 0.279 \\
\hline 2 & LEVEL & 0.033 & 0.036 & & & 0.448 & & 5.304 & 0.672 & 0.199 \\
\hline 3 & SALMON & -0.050 & 0.032 & -0.194 & & & & 6.948 & 2.317 & 0.088 \\
\hline 4 & WINTER & -0.183 & 0.028 & & & & -0.053 & 7.211 & 2.579 & 0.077 \\
\hline 5 & SUMMER & -0.137 & 0.030 & & -0.034 & & & 7.219 & 2.588 & 0.076 \\
\hline 6 & LEVEL, WINTER & -0.070 & 0.032 & & & 0.549 & -0.300 & 7.549 & 2.918 & 0.065 \\
\hline 7 & SALMON, LEVEL & 0.117 & 0.038 & -0.158 & & 0.438 & & 7.939 & 3.307 & 0.053 \\
\hline 8 & SUMMER, LEVEL & -0.035 & 0.034 & & 0.144 & 0.498 & & 7.976 & 3.344 & 0.052 \\
\hline 9 & SALMON, WINTER & -0.086 & 0.031 & -0.209 & & & -0.092 & 9.751 & 5.119 & 0.022 \\
\hline 10 & SALMON, SUMMER & -0.032 & 0.033 & -0.193 & -0.029 & & & 9.798 & 5.167 & 0.021 \\
\hline 11 & SUMMER, WINTER & -0.157 & 0.029 & & -0.082 & & -0.103 & 10.027 & 5.396 & 0.019 \\
\hline 12 & SALMON, LEVEL, WINTER & 0.026 & 0.035 & -0.206 & & 0.547 & -0.338 & 10.318 & 5.686 & 0.016 \\
\hline 13 & SUMMER, LEVEL, WINTER & -0.079 & 0.032 & & 0.031 & 0.554 & -0.283 & 10.700 & 6.068 & 0.013 \\
\hline 14 & SALMON, SUMMER, LEVEL & 0.048 & 0.036 & -0.159 & 0.144 & 0.487 & & 10.906 & 6.274 & 0.012 \\
\hline 15 & SALMON, SUMMER, WINTER & -0.050 & 0.032 & -0.216 & -0.100 & & -0.154 & 12.846 & 8.214 & 0.005 \\
\hline 16 & SALMON, SUMMER, LEVEL, WINTER & 0.022 & 0.035 & -0.205 & 0.013 & 0.550 & -0.331 & 13.826 & 9.194 & 0.003 \\
\hline
\end{tabular}

TABLE 4. Results from fitting dynamic linear models to explain lakewide variation in abundance of age-0 Bloater recruits using lakewide estimates of population egg production (EGG) in Lake Michigan for the years 1964-2008. The external variables were as follows: SEX = population sex ratio; $\mathrm{K}=$ adult condition; $\mathrm{W}-\mathrm{S}=$ index of winter and spring temperature; ALEWIFE = adult alewife biomass. Akaike's information criterion (AIC $_{c}$ ) values were used to rank the models. When the difference in $\mathrm{AIC}_{c}$ values $\left(\Delta \mathrm{AIC}_{c}\right)$ is $<2$, there is equal support for the models. Certainty in model selection was evaluated using standardized Akaike weights $\left(w_{i}\right)$, which are scaled from 0 to 1 .).

\begin{tabular}{|c|c|c|c|c|}
\hline Model rank & List of external variables & $\mathrm{AIC}_{c}$ & $\Delta \mathrm{AIC}_{c}$ & $w_{i}$ \\
\hline 1 & EGG, SEX, K, ALEWIFE & -201.73 & 0.00 & 0.52 \\
\hline 2 & EGG, SEX, ALEWIFE & -200.86 & 0.87 & 0.34 \\
\hline 3 & EGG, SEX, K, W-S & -199.09 & 2.64 & 0.14 \\
\hline 4 & EGG, SEX, K, W-S, ALEWIFE & -190.69 & 11.04 & 0.00 \\
\hline 5 & EGG, SEX, K & -188.74 & 12.99 & 0.00 \\
\hline 6 & EGG, K, W-S, ALEWIFE & -187.13 & 14.60 & 0.00 \\
\hline 7 & EGG, SEX, W-S & -166.00 & 35.73 & 0.00 \\
\hline 8 & EGG, K, ALEWIFE & -161.31 & 40.43 & 0.00 \\
\hline 9 & EGG, SEX, W-S, ALEWIFE & -155.52 & 46.22 & 0.00 \\
\hline 10 & EGG,SEX & -134.74 & 66.99 & 0.00 \\
\hline 11 & EGG, W-S, ALEWIFE & -113.99 & 87.74 & 0.00 \\
\hline 12 & EGG, ALEWIFE & -86.87 & 114.86 & 0.00 \\
\hline 13 & EGG, K, W-S & -68.85 & 132.88 & 0.00 \\
\hline 14 & EGG, K & -62.20 & 139.53 & 0.00 \\
\hline 15 & EGG, W-S & -48.46 & 153.27 & 0.00 \\
\hline 16 & & -35.39 & 166.34 & 0.00 \\
\hline 17 & EGG & -28.04 & 173.69 & 0.00 \\
\hline
\end{tabular}




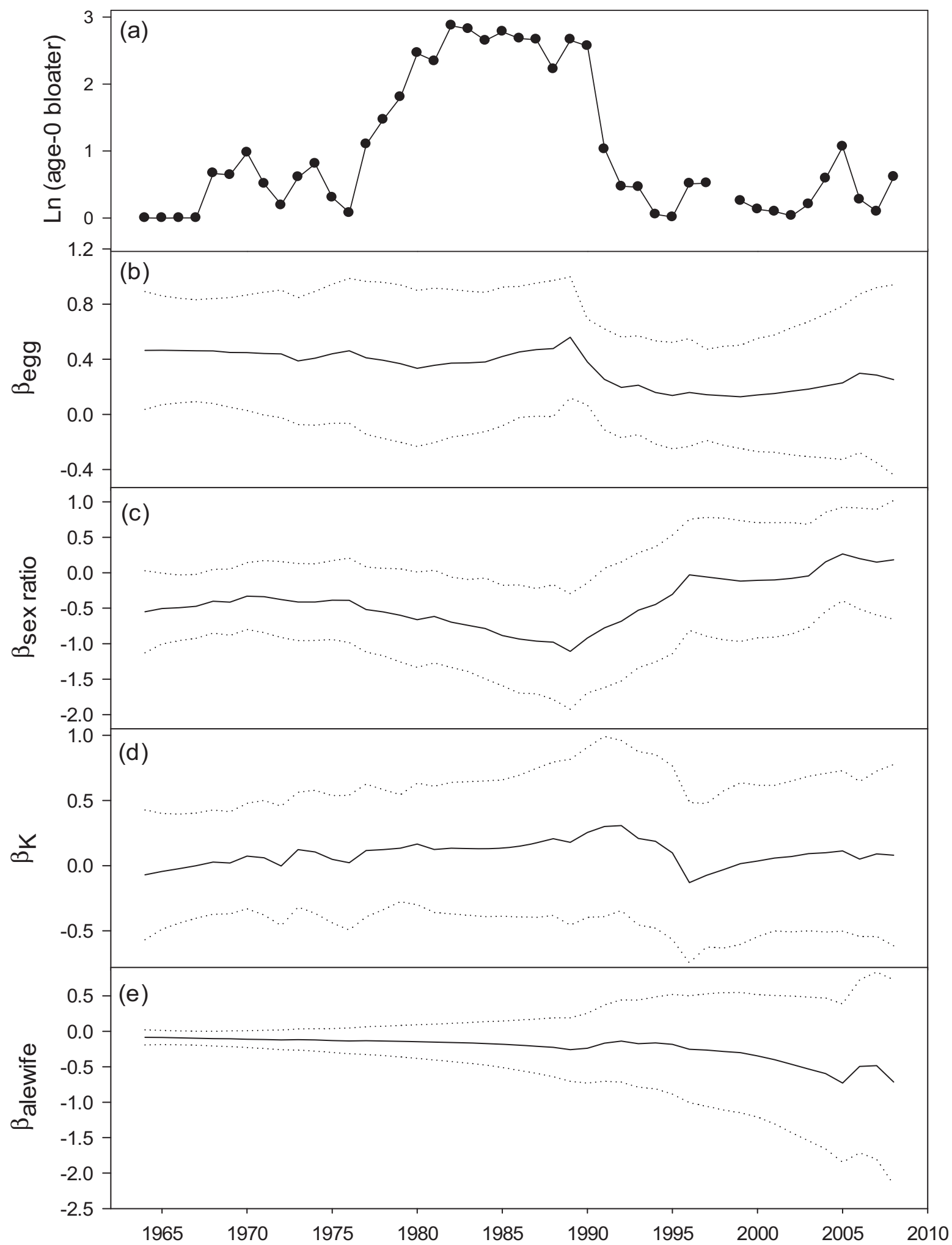

FIGURE 4. Time series results showing (a) predicted age-0 Bloater biomass based on the multimodel average of the three top-ranked dynamic linear models in Lake Michigan versus observed recruitment (dots) and the coefficients (solid lines in panels b-e) and 90\% Bayesian credible intervals (dotted line) of the top-ranked dynamic linear model. The top-ranked model in Lake Michigan included (b) population egg production, (c) population sex ratio, (d) condition of adults, and (e) Alewife abundance as explanatory variables. 


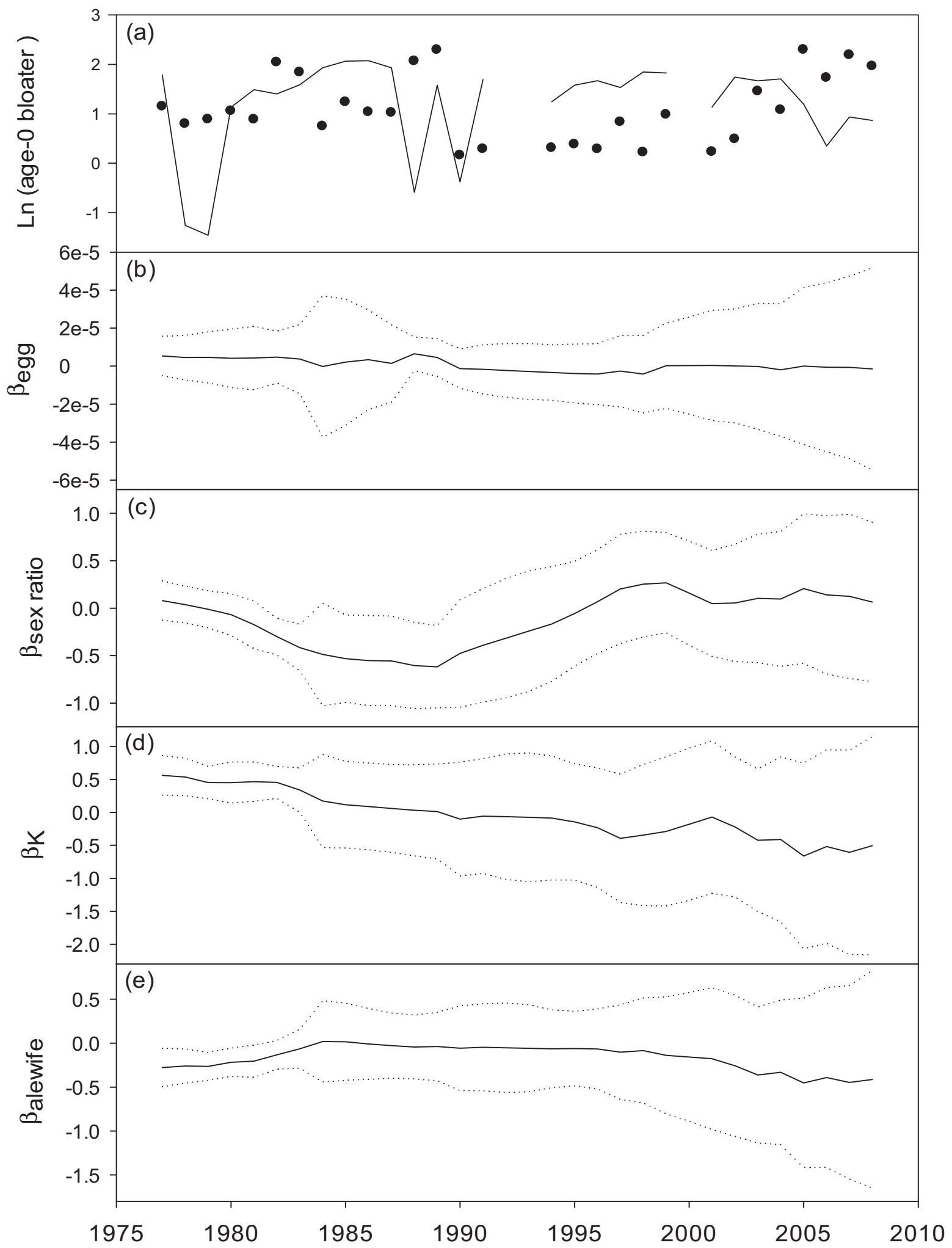

FIGURE 5. Time series results showing (a) predicted age-0 Bloater biomass based on the top-ranked dynamic linear model in Lake Huron versus observed recruitment (dots) and the coefficients (solid lines in panels b-e) and $90 \%$ Bayesian credible intervals of the explanatory variables used to predict Bloater recruitment. The top-ranked model in Lake Huron included (b) population egg production, (c) population sex ratio, (d) condition of adults, and (e) alewife abundance as explanatory variables. 
TABLE 5. Results from fitting dynamic linear models to explain lakewide variation in abundance of age-0 Bloater recruits using lakewide estimates of population egg production (EGG) in Lake Huron for the years 1977-2008. The external variables were as follows: SEX = population sex ratio; K = adult condition; W-S =

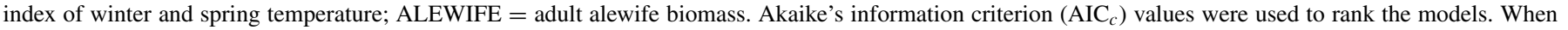
the difference in $\mathrm{AIC}_{c}$ values $\left(\triangle \mathrm{AIC}_{c}\right)$ is $<2$, there is equal support for the models. Certainty in model selection was evaluated using standardized Akaike weights $\left(w_{i}\right)$, which are scaled from 0 to 1 .).

\begin{tabular}{|c|c|c|c|c|}
\hline Model rank & List of external variables & $\mathrm{AIC}_{c}$ & $\Delta \mathrm{AIC}_{c}$ & $w_{i}$ \\
\hline 1 & EGG, SEX, K, ALEWIFE & -45.01 & 0.00 & 0.99 \\
\hline 2 & EGG, W-S, ALEWIFE & -34.73 & 10.28 & 0.01 \\
\hline 3 & EGG, SEX, K & -33.48 & 11.53 & 0.00 \\
\hline 4 & EGG,SEX & -30.13 & 14.88 & 0.00 \\
\hline 5 & EGG, SEX, K, W-S & -28.02 & 16.99 & 0.00 \\
\hline 6 & EGG, SEX, K, W-S, ALEWIFE & -27.76 & 17.25 & 0.00 \\
\hline 7 & EGG, SEX, ALEWIFE & -27.26 & 17.75 & 0.00 \\
\hline 8 & EGG, K, W-S, ALEWIFE & -24.47 & 20.54 & 0.00 \\
\hline 9 & EGG, SEX, W-S & -24.44 & 20.57 & 0.00 \\
\hline 10 & EGG, SEX, W-S, ALEWIFE & -23.55 & 21.46 & 0.00 \\
\hline 11 & EGG, K & -21.56 & 23.45 & 0.00 \\
\hline 12 & EGG, W-S & -20.31 & 24.70 & 0.00 \\
\hline 13 & EGG, ALEWIFE & -18.86 & 26.15 & 0.00 \\
\hline 14 & & -16.02 & 28.99 & 0.00 \\
\hline 15 & EGG, K, W-S & -15.18 & 29.83 & 0.00 \\
\hline 16 & EGG, K, ALEWIFE & -14.00 & 31.01 & 0.00 \\
\hline 17 & EGG & -13.67 & 31.34 & 0.00 \\
\hline
\end{tabular}

for the time series (mean of log recruits $=2.0$ in Lake Michigan). Additionally, the linear regression analyses revealed that all the candidate models from Lake Michigan had relatively high coefficients of determination $\left(R^{2}>0.4\right)$ and slopes that were close to 1.0 (Table 6). Predicted recruitment of Alewife in Lake Huron was less robust, with MSE values (1.3-1.4) approaching the mean recruitment estimate (mean $\log$ of recruits $=1.7$ ). An overall lack of predictive power for the Lake Huron Alewife recruitment models was also evident in the relatively low coef-

TABLE 6. Results of model cross-validation procedure used to determine the robustness of Alewife stock-recruit models from Lake Michigan and Lake Huron. Alewife model precision was assessed using the mean standard error (MSE) of five cross-validation runs. Cross validation was performed for each model with $\Delta \mathrm{AIC}_{c}$ values $<2$ as well as for predictions based on multimodel inference (MMI)

\begin{tabular}{llcl}
\hline & \multicolumn{3}{c}{ Alewife cross validation } \\
\cline { 2 - 4 } Model & MSE & Intercept & $R^{2}$ \\
\hline \multicolumn{4}{c}{ Lake Michigan } \\
2 & 0.679 & 0.538 & 0.437 \\
8 & 0.715 & 0.517 & 0.411 \\
13 & 0.592 & 0.595 & 0.506 \\
MMI & 0.636 & 0.525 & 0.461 \\
\multicolumn{4}{c}{ Lake Huron } \\
1 & 1.444 & 0.334 & 0.180 \\
4 & 1.314 & 0.460 & 0.305 \\
MMI & 1.264 & 0.359 & 0.231 \\
\hline
\end{tabular}

ficients of determination calculated from the linear regression analyses $\left(R^{2}=0.18-0.31\right)$, although the slopes of these regressions were close to 1.0 (Table 6). From the cross-validation results, we also found that using multimodel averaging across models to predict recruitment resulted in relatively robust recruitment estimates, with lower MSE values and comparable coefficients of determination and slopes compared with individual model results in most cases.

\section{DISCUSSION}

Variation in Bloater recruitment was explained to a much larger extent in Lake Michigan than in Lake Huron. Despite the differences in predictive power between lakes, the external factors that influenced Bloater recruitment were remarkably consistent: sex ratio, adult condition, and Alewife abundance were included in the most parsimonious models for each lake. Because the DLM updates model coefficients with each time step, we can understand how the magnitude and direction of each variable changes through time. Sex ratio, for example, was negatively related to Bloater recruitment for the majority of the time series in each lake, though its strongest effects were during 1985-1995. This result was consistent with previous modeling in Lake Michigan (Bunnell et al. 2006) and implies that the number of males somehow limits Bloater recruitment success. Whether this is, in fact, a mechanism driving recruitment variability or a spurious correlation will require improved understanding of Bloater reproductive behavior (i.e., Could the number of males limit fertilization of eggs?). The negative effect 
of Alewife on Bloater recruitment was unexpected, however, given previous modeling in Lake Michigan (Bunnell et al. 2006) and a meta-analysis that concluded that Bloater larvae were not susceptible to predation by adult Alewives (Madenjian et al. 2008). The Lake Michigan results indicated that the strongest effects of Alewife occurred in the late 2000s, when Alewife densities were about $50 \%$ lower than Alewife densities during the 1980s, when Bloater recruitment was very high. Moreover, the apparent synchrony in Bloater recruitment in Lakes Michigan, Huron, and Superior supported the contention that Alewives did not have a significantly negative effect on Bloater recruitment in Lakes Michigan and Huron, because Alewife density in Lake Superior has always been practically negligible; yet the temporal trends in Bloater recruitment have been similar across all three lakes (Madenjian et al. 2008; Bunnell et al. 2010). Therefore, in our view, the lack of a negative Alewife effect until the 2000 s suggests that this result is likely a spurious correlation. Alternatively, although less likely, the biotic interaction between Alewives and Bloaters in Lake Michigan may have changed in the 2000s such that Bloater fry became more vulnerable to Alewife predation.

Looking across the Great Lakes basin, Bloaters exhibit synchrony in recruitment across Lakes Superior, Michigan, and Huron and the simplest explanation for this was some broad regional climate driver, given that dispersal between lakes was highly unlikely (Bunnell et al. 2010). The analyses presented herein provide additional insight into this unusual synchrony pattern. First, winter and spring water temperatures did not explain recruitment variability in either lake, indicating that either we have included an inappropriate climate variable or that climate, in fact, cannot be underlying Bloater recruitment synchrony. Second, it was surprising that the same suite of key predictor variables occurred in the models for Lakes Michigan and Huron. In theory, if these variables were also synchronized across the lakes, then that could also explain synchronized recruitment patterns. A post hoc Spearman's rank correlation revealed the time series for sex ratio $\left(r_{s}=0.48, P=0.009\right)$ and adult condition $\left(r_{s}=0.57, P=0.002\right)$ to be strongly correlated between the lakes, whereas the time series for adult Alewife were not $\left(r_{s}=0.22, P=0.26\right)$. If Alewife is a spurious result, then future research will be required to improve understanding of Bloater synchrony, given the lack of variables extrinsic to the population that appear to influence Bloater recruitment.

Overall, our results on Alewife recruitment in Lake Michigan were in good agreement with the results from Madenjian et al. (2005), who used a similar approach to explain the variability in Alewife recruitment in Lake Michigan. Although the present model explained less variation in Alewife recruitment than did the previous models $(40 \%$ versus $75 \%$ of variation in age-3 Alewife recruitment explained, respectively), the results from the present model were calculated using a 10-point cross-validation procedure and are, thus, based on a more reliable method for estimating recruitment variation (Francis 2006). Just as we concluded that predation by salmonines drove the de- cline in Lake Michigan Alewife abundance during the 1970s and early 1980s, so too did Madenjian et al. (2005) conclude that predation by salmonines was the primary determinant of Alewife abundance in Lake Michigan. Further, based on estimation of the maximum reproductive rate, Madenjian at al. (2005) predicted that due to the increase in predation rate on Alewives by salmonines beginning in the late 1990s, the Alewife population in Lake Michigan would likely not be able to sustain itself under average lake temperatures. In accord with this prediction, and after allowing for the bulk of the unusually large 1998 year-class to expire, adult Alewife abundance during 2004-2011 in Lake Michigan has been maintained at a level considerably lower than the average abundance level for the 1980s and 1990s (Jacobs et al. 2013). Our modeling results indicated a positive relationship between Alewife recruitment and spring-summer water temperatures during the Alewives' first year (SUMMER) of life in six of the eight candidate recruitment models containing the SUMMER term. Similarly, Madenjian et al. (2005) found a positive relationship between Alewife recruitment and SUMMER in all eight of the candidate recruitment models containing the SUMMER term. Madenjian et al. (2005) attributed the extremely large 1998 year-classes of Alewives in both Lake Michigan and Lake Ontario to unusually warm spring-summer water temperatures in both lakes. The 1998 year-class of Alewives in Lake Michigan may have been the strongest year-class of Alewives ever produced in Lake Michigan, and coincidentally 1998 had the highest spring-summer water temperatures in the time series for Lake Michigan (Madenjian et al. 2005). Although the salmonine predation effect on Alewife recruitment was much stronger than the SUMMER effect, the SUMMER term still appeared in one of the regression model for Alewife recruitment with $\Delta \mathrm{AIC}_{c}<2$. Perhaps warm spring-summer water temperatures facilitate other factors that more directly affect Alewife survival during the first year in the lake, and therefore the correlation between Alewife recruitment and SUMMER is only of weak to moderate strength.

Our results indicated that Alewife recruitment increased with increasing severity of winter water temperatures during the Alewives' first winter in the lake (WINTER), whereas Madenjian et al. (2005) found that Alewife recruitment decreased with increasing winter severity in six of eight candidate models containing the WINTER term, although the WINTER effect was extremely weak. We believe that our results are likely due to a spurious correlation, and that Alewife recruitment does not actually increase with increasing winter severity. The recruitment modeling effort by Madenjian et al. (2005) included data for the years 1962-2002, whereas we used data for the years 1962-2008. Some of the mildest winter water temperatures in Lake Michigan on record have occurred since 2002, and these years coincided with very high rates of predation on Alewives by salmonines. Thus, the low Alewife recruitment during 20022008 was not due to mild winter water temperatures but actually due to high rates of predation by salmonines on Alewives. Alewife recruitment decreased with increasing winter severity 
in Lake Ontario and Lake Huron (O'Gorman et al. 2004; this study).

Although no strong candidate models emerged to explain Alewife recruitment in Lake Huron, water level was identified as a potential explanatory variable. Nearshore water levels may be important for Alewife spawning, and the water levels in Lakes Huron and Michigan have been lower than average for over a decade (U.S. Army Corps of Engineers, unpublished data). Adult Alewife abundance crashed to extremely low levels in 2003 and has remained very low since (Riley et al. 2008), and the association of low Alewife abundance and low water levels may be spurious. The fact that water level was not identified as a potentially important explanatory variable on Lake Michigan also suggests that the relationship may be spurious, as the two lakes share the same water level. The relatively short time series on Lake Huron, missing data, and the recent, prolonged nearabsence of Alewives from Lake Huron may pose difficulties for modeling the recruitment of this species in Lake Huron.

The complexity of the data involved and the breadth of potential external variables to include in the recruitment process make predicting fish recruitment notoriously difficult. To address the inherent complexity of the recruitment process, we used somewhat novel approaches in our analyses. First, we developed stock-recruitment models (with different approaches for different species) for two populations to make comparisons about the external variables driving recruitment success across multiple systems. Whereas recruitment predictions that are developed from a single population at a particular time may have limited application, our results, based on multiple populations, should be applicable to Alewife and Bloater populations across a broader geographical scale. Next, when models in the candidate set produced similar results, we accounted for model selection uncertainty by using multimodel averages to predict recruitment for Alewife and Bloater. The concept of model averaging is not entirely new; AIC-based methods similar to the ones presented here have been used to estimate growth parameters (Katsanevakis 2006) and Bayesian model averaging has been used to predict Walleye recruitment in Lake Erie (Jiao et al. 2009). However, these methods are likely underutilized in fisheries studies, particularly when compared with the popularity of AIC to determine the "best model." In addition to multimodel averaging, we also used summed Akaike weights from all of the candidate models to infer the importance of the external variables in the recruitment models. To our knowledge, the use of summed Akaike weights to determine the relative importance of external variables has not been used in any similar recruitment studies. We encourage future studies to apply these methods to make full use of the information theoretic approach outlined in Burnham and Anderson (2002). As a final step, we attempted to check the predictive ability of our models using a crossvalidating procedure. Although the time-specific nature of the DLM approach used to predict Bloater recruitment precluded cross validation for these models, we were able to cross vali- date the Ricker models used to predict Alewife recruitment. Our results demonstrate that predicted recruitment based on multimodel averaging can provide accurate results compared with recruitment predictions from single models, even after accounting for model-selection uncertainty. Model cross validation is not typically done with fisheries models, although several excellent examples of the methodology for cross validation are available in the fisheries literature (Francis 2006).

In conclusion, we found that Alewife and Bloater recruitment dynamics over multiple decades in Lakes Michigan and Huron are predominantly regulated by biological interactions and demographic trends, respectively. These results are consistent with the paradigm that recruitment variability of freshwater fish is regulated by biotic influences, whereas recruitment in marine systems is regulated by climatic influences (Myers et al. 1997). Our results are also in agreement with previous analyses on these species in a single system, but our finding of consistent results across a longer time series reinforces the importance of these factors in predicting fish recruitment. We were unable to find a definitive link between climatic factors and recruitment success of Bloater or Alewife in either system. In retrospect, the lack of climatic influence over recruitment in our analyses may be related to the particular type of models that were used rather than the importance of these variables for predicting recruitment success in the Great Lakes. While analyses using long-standing time series data are commonly used to elicit information about recruitment dynamics, they are ultimately designed to identify the main factors that influence recruitment over the entire time series. Factors that have a more subtle influence on recruitment are less likely to be included in the top-rated models in such an analysis. Moreover, the time series of climatic variables may lack sufficient contrast to detect significant climate effects on recruitment because significant warming occurs mainly towards the end of the time series. Regardless of the limitations of these methods, there is a need to provide accurate predictions about the potential for a changing climate to influence fish recruitment. For future studies, researchers should also consider using mechanistic models, such as fish bioenergetics models, to predict the effects of climate change on fish recruitment in the Great Lakes.

\section{ACKNOWLEDGMENTS}

The authors thank the scientific staff, captains, and crew for their efforts maintaining the long-term data sets on Lakes Michigan and Huron. David Warner, Derek Aday, and three anonymous reviewers provided helpful reviews of the manuscript. Funding for this work was provided by the U.S. Geological Survey, National Climate Change and Wildlife Science Center. Any use of trade, product, or firm names is for descriptive purposes only and does not imply endorsement by the U.S. Government. This article is Contribution 1779 of the U.S. Geological Survey Great Lakes Science Center. 


\section{REFERENCES}

Adams, J. V., S. C. Riley, and S. A. Adlerstein. 2009. Development of fishing power corrections for 12-m Yankee and 21-m wing bottom trawls used in Lake Huron. Great Lakes Fishery Commission Technical Report 68.

Akaike, H. 1973. Information theory and an extension of the maximum likelihood principle. Pages 267-281 in B. N. Petrov and F. Csáki, editors. Proceedings of the second international symposium on information theory. Akademiai Kiado, Budapest.

Barbiero, R. P., B. M. Lesht, and G. J. Warren. 2012. Convergence of trophic state and the lower food web in Lakes Huron, Michigan and Superior. Journal of Great Lakes Research 38:368-380.

Benjamin, D. M., and J. R. Bence. 2003. Statistical catch-at-age framework for Chinook Salmon in Lake Michigan, 1985-1996. Michigan Department of Natural Resources, Fisheries Division, Research Report 2066, Lansing.

Brown, E. H., Jr. 1972. Population biology of Alewives, Alosa pseudoharengus, in Lake Michigan, 1949-70. Journal of the Fisheries Research Board of Canada 29:477-500.

Bunnell, D. B., J. V. Adams, O. T. Gorman, C. P. Madenjian, S. C. Riley, E. F. Roseman, and J. S. Schaeffer. 2010. Population synchrony of a native fish across three Laurentian Great Lakes: evaluating the effects of dispersal and climate. Oecologia 162:641-651.

Bunnell, D. B., R. P. Barbiero, S. A. Ludsin, C. P. Madenjian, G. J. Warren, D. M. Dolan, T. O. Brenden, R. Briland, O. T. Gorman, J. X. He, T. H. Johengen, B. F. Lantry, T. F. Nalepa, S. C. Riley, C. M. Riseng, T. J. Treska, I. Tsehaye, D. M. Warner, M. G. Walsh, and B. C. Weidel. In press. Evaluating bottomup and top-down regulation in Great Lakes food webs. BioScience. DOI: 10.1093/biosci/bit001.

Bunnell, D. B., S. R. David, and C. P. Madenjian. 2009. Decline in Bloater fecundity in southern Lake Michigan after decline of Diporeia. Journal of Great Lakes Research 35:45-49.

Bunnell, D. B., C. P. Madenjian, and T. E. Croley II. 2006. Long-term trends of Bloater (Coregonus hoyi) recruitment in Lake Michigan: evidence for the effect of sex ratio. Canadian Journal of Fisheries and Aquatic Sciences 63:832-844.

Bunnell, D. B., C. P. Madenjian, T. J. Desorcie, M. J. Kostich, K. R. Smith, and J. V. Adams. 2013. Status and trends of prey fish populations in Lake Michigan, 2012. Report presented at Great Lakes Fishery Commission, Lake Michigan Committee Meeting, Duluth, Minnesota. Available: www.glsc.usgs.gov/sites/default/files/product_files/2012LakeMichiganPrey fish.pdf. (March 2013).

Burnham, K. P., and D. R. Anderson. 2002. Model selection and multimodel inference: a practical information-theoretic approach, 2nd edition. SpringerVerlag, New York.

Croley, T. E. II. 1995. Laurentian Great Lakes dynamics, climate, and response to change. Pages 253-296 in H. R. Oliver and S. A. Oliver, editors. The role of water and the hydrological cycle in global change. Global environmental change, volume 31. Springer-Verlag, NATO Advanced Science Institutes Series 1, Berlin.

DeVries, D. R., and R. V. Frie. 1996. Determination of age and growth. Pages 483-512 in B. R. Murphy and D. W. Willis, editors. Fisheries techniques, 2nd edition. American Fisheries Society, Bethesda, Maryland.

Emery, L., and E. H. Brown Jr. 1978. Fecundity of the Bloater (Coregonus hoyi) in Lake Michigan. Transactions of the American Fisheries Society 107:785789.

Fleischer, G. W., C. P. Madenjian, T. J. DeSorcie, and J. D. Holuszko. 2000. Status and trends of prey fish populations in Lake Michigan, 1999. Report presented at Great Lakes Fishery Commission, Lake Michigan Committee Meeting, Ann Arbor, Michigan.

Francis, R. I. C. C. 2006. Measuring the strength of environmentrecruitment relationships: the importance of including predictor screening within cross-validations. ICES Journal of Marine Science 63: 594-599.

Hilborn, R. and M. Mangel. 1997. The ecological detective: confronting models with data. Princeton University Press, Princeton, New Jersey.
Hilborn, R., and C. J. Walters. 1992. Quantitative fisheries stock assessment: choice, dynamics and uncertainty. Chapman and Hall, New York.

Jacobs, G. R., C. P. Madenjian, D. B. Bunnell, D. M. Warner, and R. M. Claramunt. 2013. Chinook Salmon foraging patterns in a changing Lake Michigan. Transactions of the American Fisheries Society 142:362-372.

Jiao, Y., K. Reid, and E. Smith. 2009. Model selection uncertainty and Bayesian model averaging in fisheries recruitment modeling. Pages 505-524 in R. J. Beamish and B. J. Rothschild, editors. The future of fisheries science in North America. Springer, New York.

Katsanevakis, S. 2006. Modelling fish growth: model selection, multi-model inference and model selection uncertainty. Fisheries Research 81:229-235.

Langley, A., K. Briand, D. S. Kirby, and R. Murtugudde. 2009. Influence of oceanographic variability on recruitment of Yellowfin Tuna (Thunnus albacares) in the western and central Pacific Ocean. Canadian Journal of Fisheries and Aquatic Sciences 66:1462-1477.

Lester, S. E., K. L. McLeod, H. Tallis, M. Ruckelshaus, B. S. Halpern, P. S. Levin, F. P. Chavez, C. Pomeroy, B. J. McCay, C. Costello, S. D. Gaines, A. J. Mace, J. A. Barth, D. L. Fluharty, and J. K. Parrish. 2010. Science in support of ecosystem-based management for the US West Coast and beyond. Biological Conservation 143:576-587.

Madenjian, C. P., D. B. Bunnell, J. D. Holuszko, T. J. Desorcie, and J. V. Adams. 2010. Status and trends of prey fish populations in Lake Michigan, 2009. U.S. Geological Survey, Great Lakes Science Center, Ann Arbor, Michigan.

Madenjian, C. P., T. O. Höök, E. S. Rutherford, D. M. Mason, T. E. Croley II, E. B. Szalai, and J. R. Bence. 2005. Recruitment variability of Alewives in Lake Michigan. Transactions of the American Fisheries Society 134: 218-230.

Madenjian, C. P., R. O'Gorman, D. B. Bunnell, R. L. Argyle, E. F. Roseman, D. M. Warner, J. D. Stockwell, and M. A. Stapanian. 2008. Adverse effects of Alewives on Laurentian Great Lakes fish communities. North American Journal of Fisheries Management 28:263-282.

Madenjian, C. P., J. T. Tyson, R. L. Knight, M. W. Kershner, and M. J. Hansen. 1996. First-year growth, recruitment, and maturity of Walleyes in western Lake Erie. Transactions of the American Fisheries Society 125:821-830.

Myers, R. A. 1998. When do environment-recruitment correlations work? Reviews in Fish Biology and Fisheries 8:285-305.

Myers, R. A., G. Mertz, and J. Bridson. 1997. Spatial scales of interannual recruitment variations of marine, anadromous, and freshwater fish. Canadian Journal of Fisheries and Aquatic Sciences 54:1400-1407.

Nalepa, T. F., D. L. Fanslow, and G. A. Lang. 2009. Transformation of the offshore benthic community in Lake Michigan: recent shift from the native amphipod Diporeia spp. to the invasive mussel Dreissena rostriformis bugensis. Freshwater Biology 54:466-479.

Norden, C. R. 1967. Age, growth and fecundity of the Alewife, Alosa pseudoharengus (Wilson), in Lake Michigan. Transactions of the American Fisheries Society 96:387-393.

O'Gorman, R., B. F. Lantry, and C. P. Schneider. 2004. Effect of stock size, climate, predation, and trophic status on recruitment of Alewives in Lake Ontario, 1978-2000. Transactions of the American Fisheries Society 133:855867.

O'Gorman, R., and C. P. Schneider. 1986. Dynamics of Alewives in Lake Ontario following a mass mortality. Transactions of the American Fisheries Society 115:1-14.

Pole, A., M. West, and J. Harrison. 1994. Applied Bayesian forecasting and time series analysis. Chapman and Hall, New York.

R Development Core Team. 2008. R: a language and environment for statistical computing. R Foundation for Statistical Computing, Vienna. Available: www.R-project.org. (March 2013).

Rice, J. A., L. B. Crowder, and M. E. Holey. 1987. Exploration of mechanisms regulating larval survival in Lake Michigan Bloater: a recruitment analysis based on characteristics of individual larvae. Transactions of the American Fisheries Society 116:703-718.

Ricker, W. E. 1975. Computation and interpretation of biological statistics of fish populations. Fisheries Research Board of Canada Bulletin 191. 
Riley, S. C., E. F. Roseman, J. V. Adams, T. P. O'Brien, and S. A. Farha. 2009. Status and trends of the Lake Huron offshore demersal fish community, 1976-2009. U.S. Geological Survey, Great Lakes Science Center, Ann Arbor, Michigan.

Riley, S. C., E. F. Roseman, S. J. Nichols, T. P. O'Brien, C. S. Kiley, and J. S. Schaeffer. 2008. Deepwater demersal fish community collapse in
Lake Huron. Transactions of the American Fisheries Society 137:18791890.

Schaeffer, J. S. 2004. Population dynamics of Bloaters Coregonus hoyi in Lake Huron, 1980-1998. Annales Zoologici Fennici 41:271-279.

Walters, C. J., and S. J. D. Martell. 2004. Fisheries ecology and management. Princeton University Press, Princeton, New Jersey. 